\title{
Direct growth of carbon nanotubes on carbon fibers: Effect of the CVD parameters on the degradation of mechanical properties of carbon fibers
}

\author{
Niels De Greef ${ }^{\mathrm{a}}$, Luman Zhang ${ }^{\mathrm{a}}$, Arnaud Magrez ${ }^{\mathrm{b}}$, László Forró ${ }^{\mathrm{b}}$, Jean-Pierre Locquet ${ }^{\mathrm{c}}$, \\ Ignaas Verpoest ${ }^{\mathrm{a}}$, Jin Won Seo ${ }^{\mathrm{a}, *}$ \\ a Department of Materials Engineering, KU Leuven, Kasteelpark Arenberg 44 - bus 2450, B-3001 Leuven, Belgium \\ b Institute of Condensed Matter Physics, Ecole Polytechnique Fédérale de Lausanne, CH-1015 Lausanne, Switzerland \\ c Laboratory of Solid-State Physics and Magnetism, KU Leuven, Celestijnenlaan 200D, B-3001 Leuven, Belgium
}

\section{A R T I C L E I N F O}

\section{Article history:}

Received 6 August 2014

Received in revised form 17 October 2014

Accepted 7 November 2014

Available online 11 November 2014

\section{Keywords:}

Carbon nanotubes

carbon fibers

carbon fiber reinforced composites

CVD

\begin{abstract}
A B S T R A C T
Grafting carbon nanotubes (CNTs) directly on carbon fibers represents a promising approach in order to strengthen the weak interface between carbon fibers and polymer matrix in carbon fiber reinforced polymer composites (CFRCS). We have carried out direct growth of CNTs on carbon fibers by using two different catalytic chemical vapor deposition (CVD) processes, namely the conventional CVD process based on catalytic thermal decomposition of ethylene and the oxidative dehydrogenation reaction between acetylene and carbon dioxide. The effect of various CVD growth parameters, such as temperature, catalyst composition and process gas mixture, was for the first time systematically studied for both processes and correlated with the mechanical properties of carbon fibers derived from single-fiber tensile tests. The growth temperature was found to be the most critical parameter in the presence of catalyst particles and reactive gasses for both processes. The oxidative dehydrogenation reaction enabled decreasing CNT growth temperature as low as $500^{\circ} \mathrm{C}$ and succeeded to grow CNTs without degradation of carbon fiber's mechanical properties. The Weibull modulus even increased indicating partial healing of present defects during the CVD process. The new insights gained in this study open a way towards simple, highly reproducible and up-scalable process of grafting CNTs on carbon fibers without inducing any damages during the CVD process. This represents an important step towards CNT-reinforced CFRCs with higher damage resistance.
\end{abstract}

(c) 2014 Elsevier B.V. All rights reserved.

\section{Introduction}

Carbon fiber reinforced polymer composites (CFRCs) have been gaining their importance in structural applications where weight saving is an important issue. However, their damage resistance has been up to now rather limited which makes them prone to early fiber/matrix debonding, consequent transverse cracks, and delamination. This limited damage resistance is currently compensated by over-dimensioning the composite parts, which counteracts the benefit of using lightweight composite materials. One of the most promising approaches to improve their damage resistance represents nano-engineering of CFRCs. Because of their excellent mechanical properties, low density and high aspect ratio, carbon nanotubes (CNTs) have been considered as promising in this research area [1-5]. CNTs can be introduced into CFRCs in a variety of ways: dispersed in the resin [6-8], introduced as a CNT layer between the fiber layers $[9,10]$ or grown directly on the carbon fiber surface. The idea of growing CNTs on carbon fibers goes back to the work of Downs

\footnotetext{
* Corresponding author. Tel.: + 3216321272.

E-mail address: maria.seo@mtm.kuleuven.be (J.W. Seo).
}

and Baker [11,12] in the early 90s and has been since then further explored by a few groups [13-23].

Grafting CNTs on carbon fibers affects directly the fiber/matrix interface, which represents the main weak spot where mostly the damage initiation takes place. However, growing CNTs by means of chemical vapor deposition (CVD) is not straightforward but strongly depends on the precise process conditions. Most of the previous studies faced the severe drawback of damaging the carbon fiber surface during the growth process of CNTs and degrading the initial mechanical properties of carbon fibers [13-18]. The interplay between high temperature, reactive gasses and catalytic particles during the CNT growth process has been considered to be responsible for this phenomenon. Only a few groups have reported no degradation [19] or even improved tensile strength [20,21]. Particularly, the recent works of Kim et al. suggest healing mechanisms of carbon fiber surfaces during the catalytic growth of CNTs [21-23] and demonstrate that the grafting of CNTs can be a feasible approach for tailoring the interfacial properties without compromising the tensile strength of carbon fibers.

Nevertheless, in order to synthesize CNT-grafted CFRCs on a large scale, a CNT growth process is required that is strongly reproducible 
and easy to control. Preventing damage to the initial carbon fiber structure may be beneficial for a higher controllability of the carbon fiber characteristics. Very recently, we have reported about grafting CNTs on carbon fibers by using a CVD process based on the oxidative dehydrogenation reaction between $\mathrm{C}_{2} \mathrm{H}_{2}$ and $\mathrm{CO}_{2}$, that allowed us growing CNTs on carbon fibers at $500{ }^{\circ} \mathrm{C}$ without any deterioration of the carbon fiber structure and degradation of the mechanical properties [24]. In this paper, we compare two processes of growing CNTs directly on carbon fibers, namely (i) the conventional process based on the thermal decomposition of ethylene and (ii) the oxidative dehydrogenation reaction between $\mathrm{C}_{2} \mathrm{H}_{2}$ and $\mathrm{CO}_{2}$. We have systematically studied the influence of the growth parameters, such as temperature, catalyst composition as well as gas mixture, both on resulting CNT characteristics and the mechanical properties of CNT-grafted carbon fibers. The growth temperature was identified as the most critical parameter for both processes when catalyst particles and reactive gasses were present. Consequently, the oxidative dehydrogenation reaction between $\mathrm{C}_{2} \mathrm{H}_{2}$ and $\mathrm{CO}_{2}$ carried out at low temperatures, such as $500{ }^{\circ} \mathrm{C}$ and $600{ }^{\circ} \mathrm{C}$, yielded CNT grafted carbon fibers without any deterioration of the carbon fiber or degradation of the mechanical properties. The detailed Weibull analysis showed that the Weibull modulus increased indicating defects partially recovered during the catalytic CVD process. These results demonstrate for the first time that the oxidative dehydrogenation reaction is a highly promising CVD process for grafting CNTs on carbon fibers. Being a viable, reproducible and simple process, it can also easily be scaled up for the development of CNT-engineered CFRCs with high damage resistance.

\section{Experimental section}

\subsection{Materials}

The carbon fibers used throughout this study were AS4C PAN-based carbon fibers, arranged in bundles of 6000 fibers (G0986 injectex, Hexcel). According to the manufacturer's datasheet, the fibers have a Young's modulus of $231 \mathrm{GPa}$, tensile strength of $4385 \mathrm{MPa}$ and strainto-failure of about $1.8 \%$.

\subsection{Carbon fiber treatment prior to CNT growth}

Before depositing catalyst particles on the carbon fibers, the polymer sizing on the surface was removed by heating them at $450^{\circ} \mathrm{C}$ for $15 \mathrm{~min}$. This temperature was suggested by the ASTM D3379 standard and also verified by TGA measurements (Supporting information, Fig. S1), which showed that the polymer sizing fully decomposed in an inert atmosphere at around $360{ }^{\circ} \mathrm{C}$. In literature, the presence of $\mathrm{N}-\mathrm{C}=\mathrm{O}$, $\mathrm{O}-\mathrm{C}=\mathrm{O}$ and $\mathrm{C}=\mathrm{O}$ have been identified as the main functional groups present on carbon fibers with and without sizing $[25,26]$. These active sites may facilitate attachment of catalysts on the carbon fiber surface, but they can also promote structural damages to the carbon fiber surface. Therefore, the removal of the sizing was specifically carried out in argon atmosphere in order to strongly limit the number of additional active functional groups.

The catalyst for CNT growth originated from mono- and bi-metallic salt solutions prepared by dissolving $\mathrm{Fe}(\mathrm{III})$ nitrate nonahydrate, $\mathrm{Ni}$ (III) nitrate hexahydrate and $\mathrm{Co}$ (III) nitrate hexahydrate in ethanol. In the bimetallic case, the $\mathrm{Fe} / \mathrm{Co}$ or $\mathrm{Fe} / \mathrm{Ni}$ ratio was fixed to $2: 1$ in order to reach the composition of the most active catalyst in the Fe-Co and Fe-Ni system, respectively [27]. The catalyst compositions explored in this study were $\mathrm{Fe}, \mathrm{Ni}, \mathrm{Co}, \mathrm{Fe}_{2} \mathrm{Ni}$ and $\mathrm{Fe}_{2} \mathrm{Co}$. Carbon fiber bundles (not individually separated fibers) were impregnated with the catalyst solution by dipping and immersing for about $16 \mathrm{~h}$. Subsequently, the bundles were taken out from the solution. After wiping off excess solution with paper, the bundles were dried in an oven at $80^{\circ} \mathrm{C}$ for $2 \mathrm{~h}$.

\subsection{CNT growth process}

Multi-walled CNTs (MWCNTs) were synthesized on catalyst particles, deposited on the carbon fiber surface, by means of an ambient pressure CVD reactor. The CVD system consisted of a horizontal tubular furnace with a three-zone heating and a quartz tube with a diameter of $70 \mathrm{~mm}$. The carbon fiber bundles were first placed in the cold part of the quartz tube (outside the heated zone) while purging the quartz tube with $\mathrm{N}_{2}$ first and subsequently with Ar gas for $5 \mathrm{~min}$. Then the fibers were pushed to the middle zone of the CVD furnace and, after purging for another $5 \mathrm{~min}$ with $\mathrm{Ar}$, the reactive gasses were injected into the quartz tube. At the end of the growth process, the reactive gasses were removed from the quartz tube by further purging with Ar. The carbon fibers were then moved to the cold part of the quartz tube (outside the heated zone) to cool down. The gas mixtures used for our studies were as follows: (i) conventional CNT growth based on the catalytic thermal decomposition of $\mathrm{C}_{2} \mathrm{H}_{4}$ using $\mathrm{Ar}, \mathrm{C}_{2} \mathrm{H}_{4}$ and $\mathrm{H}_{2}$ for 10 min with ratio 10:1:1 and (ii) oxidative dehydrogenation of $\mathrm{C}_{2} \mathrm{H}_{2}$ and $\mathrm{CO}_{2}$ using an equimolar ratio of $\mathrm{C}_{2} \mathrm{H}_{2}$ and $\mathrm{CO}_{2}$ with exposure to $\mathrm{Ar}, \mathrm{C}_{2} \mathrm{H}_{2}$ and $\mathrm{CO}_{2}$ for $30 \mathrm{~min}$ (ratio 45:1:1). For the second process, also the influence of $\mathrm{H}_{2}$ was investigated, which was added during the purging with $\mathrm{Ar}$ after insertion of the carbon fibers into the heated zone. The $\mathrm{Ar}: \mathrm{H}_{2}$ ratio was kept to $10: 1$. These processes were carried out for a temperature range of $400-750{ }^{\circ} \mathrm{C}$ and for the different catalyst composition mentioned above. Both CVD processes are denoted as "conventional growth" and "equimolar growth", respectively, throughout the whole manuscript.

\subsection{Characterization techniques}

CNT-grafted carbon fibers were imaged with scanning electron microscope (SEM) using a Philips XL30 FEG microscope operating at $10 \mathrm{kV}$. CNTs were also studied by means of a transmission electron microscope (TEM), namely Philips CM200 FEG operating at an acceleration voltage of $200 \mathrm{kV}$. TEM samples were prepared by gluing individual carbon fibers grafted with CNTs on a half copper TEM ring. TEM images were used to determine the CNT diameter and its distribution. Raman spectroscopy was performed by means of a confocal Raman spectrometer (LabRam HR from Horiba) using a $532 \mathrm{~nm}$ laser and a 100× objective lens (spot size of $0.3 \mu \mathrm{m}$ ).

To assess the extent of damage caused by the CNT growth process, single-fiber tensile tests were carried out according to the ASTM D3379 standard with a gauge length of $25 \mathrm{~mm}$ and a crosshead speed of $500 \mu \mathrm{m} / \mathrm{min}$. A $18 \mathrm{~N}$ load cell with a resolution of $1 \mu \mathrm{N}$ and a crosshead displacement with a resolution of $1 \mathrm{~nm}$ were used to record force and displacement, which were converted to stress and strain. Before each test, exact gauge length was measured automatically by the set-up (Q800, TA Instruments). The cross-sectional area of the fibers was measured by means of SEM (diameter of $7 \mu \mathrm{m}$, cross-sectional area of $38.5 \mu \mathrm{m}^{2}$ ) and was considered as the same for all fibers since the deviation was rather small. Strength was taken as the maximum stress and the strain-to-failure as the maximum strain at break. Stiffness was determined as the tangent slope of the stress-strain curve between 0.1 and $0.3 \%$ strain (see Supporting information, Fig. S2). At least 15 fibers were tested for each sample. The adhesion strength between carbon fiber and CNTs was qualitatively assessed by exposing CNT-grafted fibers to ultra-sonication for $30 \mathrm{~min}$ in ethanol at room temperature and $40 \mathrm{kHz}$. SEM images were taken before and after sonication.

\section{Results and discussion}

\subsection{Influence of gas mixture and process temperature}

SEM images of the carbon fibers after removal of sizing and the carbon fibers after CVD process at $700{ }^{\circ} \mathrm{C}$ using Co catalyst are shown in Fig. 1. A relatively smooth surface of the unprocessed carbon fibers 

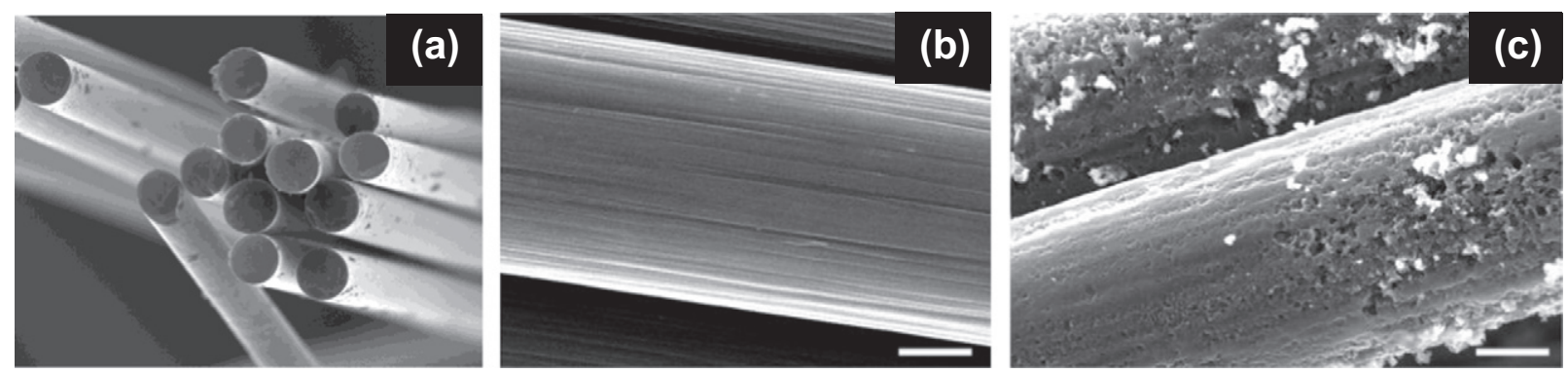

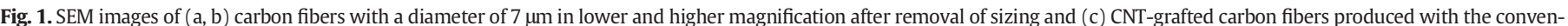

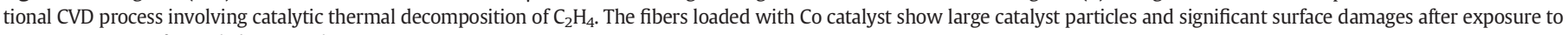
$\mathrm{Ar} / \mathrm{H}_{2} / \mathrm{C}_{2} \mathrm{H}_{4}$ at $700{ }^{\circ} \mathrm{C}$. Scale bars equal $2 \mu \mathrm{m}$.

can be seen with typically well-defined striation parallel to the fiber axis as well as a few debris attached to the surface, both originating from the manufacturing process. In contrast, the carbon fibers after conventional CVD process (Fig. 1c) show surface pitting: in the area without large catalyst particles, pits are preferentially located along the striation, deepening and roughening the initial striation. At the fiber surface with many large catalyst particles (bright contrast in the SEM image) the pitting is significantly deeper and densely distributed. This observation indicates that excessive etching of the carbon fiber surface occurred at large catalyst particles, as will be explained later in the text.

As a simple monitoring of the CNT growth and the surface etching, the weight of the carbon fibers prior to the CVD process was measured after catalyst impregnation and subsequent drying. This initial value was then compared with the weight measured directly after the CVD process. Fig. 2 summarizes this weight difference for the CVD processes carried out at different temperatures and for different gas mixtures. The weight difference $\Delta \mathrm{w}$ is given in $\%$ with $\Delta \mathrm{w}=\left(\mathrm{w}_{\mathrm{i}}-\mathrm{w}_{\mathrm{f}}\right) / \mathrm{w}_{\mathrm{i}}$, with $\mathrm{w}_{\mathrm{i}}$ and $\mathrm{w}_{\mathrm{f}}$ being the initial and the final weight measured (before and after CVD process), respectively. For comparison, also the weight differences of the impregnated carbon fibers that were heated without any carbon precursors, namely only in $\mathrm{Ar}$ or $\mathrm{Ar} / \mathrm{H}_{2}$ atmosphere, are included in Fig. 2.

\subsubsection{Conventional growth}

The graph for the conventional CVD process is similar to that exposed to $\mathrm{Ar}$ or $\mathrm{Ar} / \mathrm{H}_{2}$ but completely different from that of the equimolar growth. It is surprising that all these graphs (except that of the equimolar growth) indicate a weight loss of about $1-2 \%$ already at 500 ${ }^{\circ} \mathrm{C}$. A possible explanation for this weight loss might be found for

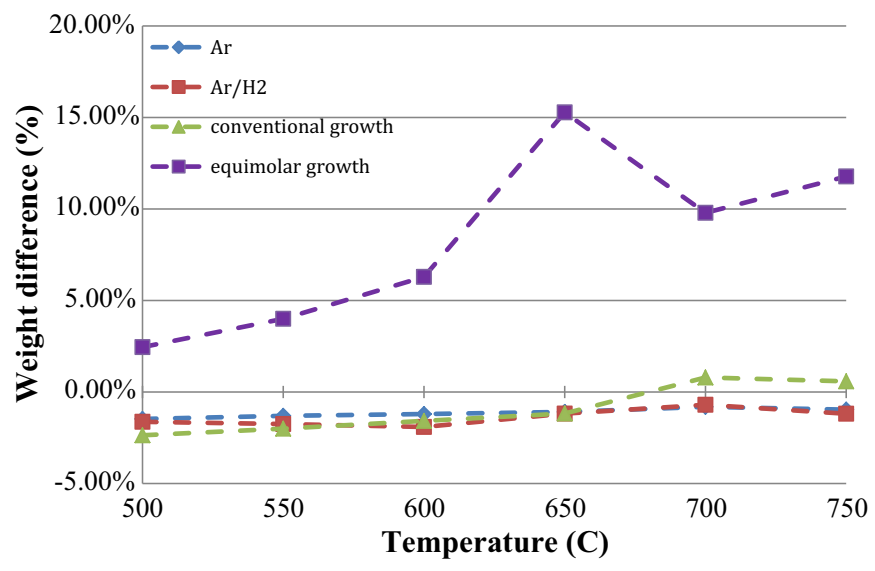

Fig. 2. The weight difference of carbon fibers before and after the CVD process is highlighted as a function of CVD temperature for different treatments. All fibers were impregnated with $\mathrm{Fe}_{2} \mathrm{Ni}$ catalyst. The fibers exposed to the gas mixture used for the conventional CNT growth $(\Delta)$ and for the equimolar $\mathrm{C}_{2} \mathrm{H}_{2}-\mathrm{CO}_{2}$ reaction ( $\square$ ) are shown. For comparison, the weight difference obtained after the exposure to only $\operatorname{Ar}(\Delta)$ or $\mathrm{Ar} / \mathrm{H}_{2}(\mathbf{\square})$ is included. instance in the removal of residual solvents from the catalyst preparation, in the reduction of the catalyst particles from oxides and hydroxides to metallic particles, or in the reaction of carbon fibers with the gas environment as well as with the catalyst. However, it also has to be noted that carbon fibers generally experience a weight loss at high temperatures. Whereas the etching of the graphitic structure occurs at temperatures higher than $600{ }^{\circ} \mathrm{C}$, our TGA measurements (see Supporting information, Fig. S1) indicated a weight loss of a few \% already at $400{ }^{\circ} \mathrm{C}$. Hoffman et al. observed a weight loss of $0.76 \%$ upon heating to $550{ }^{\circ} \mathrm{C}$ in air and suggested that this weight loss was due to etching of the carbon fiber surface at chemically active sites and disordered regions [28]. Such etching can originate for instance from the removal of amorphous carbon, chemical functional groups and/or thin flakes present on the carbon surface (see Fig. 1a). These "surface dirts" have frequently been observed as debris from the carbon fiber production process [29].

For conventional growth, this weight loss was even more pronounced at $500{ }^{\circ} \mathrm{C}$, namely about $2.5 \%$, but slowly decreased with temperature. Although the differences in weight loss are rather small for the three graphs ( $\mathrm{Ar}, \mathrm{Ar} / \mathrm{H}_{2}$ exposure and conventional growth), the trend is clear: at temperatures below $600{ }^{\circ} \mathrm{C}$, exposure to Ar resulted in the least pronounced weight loss whereas the conventional growth led to the highest weight loss. Thus, a stronger etching occurred for $\mathrm{Ar} / \mathrm{H}_{2}$ exposure and conventional growth compared to Ar exposure only. Taking the SEM observations (see Fig. 1c) into account, which show that large catalyst particles generated the largest pits on carbon fibers, we can conclude that the interplay between catalyst particles, carbon fiber and the reaction gas composition strongly determined the etching behavior. As $\mathrm{H}_{2}$ and $\mathrm{C}_{2} \mathrm{H}_{4}$ strongly reduce oxidized catalysts to metallic particles, local release of oxygen may be promoted that can etch the carbon fiber surface into deep pits. Scanning tunneling microscopy studies [28-30] illustrated that the presence of oxygen at elevated temperatures could strongly promote etching of the carbon fiber surface. Although more detailed studies need to follow, this may explain why the etching was more pronounced to $\mathrm{Ar} / \mathrm{H}_{2}$ and $\mathrm{C}_{2} \mathrm{H}_{4}$ exposure and also more promoted around large catalyst particles, where also higher amount of oxygen was supposed to become free compared to small particles.

Between $650{ }^{\circ} \mathrm{C}$ and $700{ }^{\circ} \mathrm{C}$ the weight difference evolved clearly differently for the conventional growth: It is positive due to the fact that the catalytic decomposition of hydrocarbon gas was thermally activated and initiated the growth of CNTs. The weight gain reached its maximum with about $1 \%$ increase at $700{ }^{\circ} \mathrm{C}$. The SEM images presented in Fig. 3 highlight the evolution of the weight gain: After processing at $650{ }^{\circ} \mathrm{C}$, carbon fibers were covered with a few CNTs, mainly between carbon fibers, whereas $700{ }^{\circ} \mathrm{C}$ yielded CNTs homogenously covering the surface of carbon fibers. A very limited number of CNTs were present after the growth at $750{ }^{\circ} \mathrm{C}$, mainly situated between the fibers and with a diameter of about $100-200 \mathrm{~nm}$, much larger than those obtained at $700{ }^{\circ} \mathrm{C}$. For the whole temperature range, catalyst particles were preferentially found at the end of CNTs (observed by SEM) indicating low chemical 

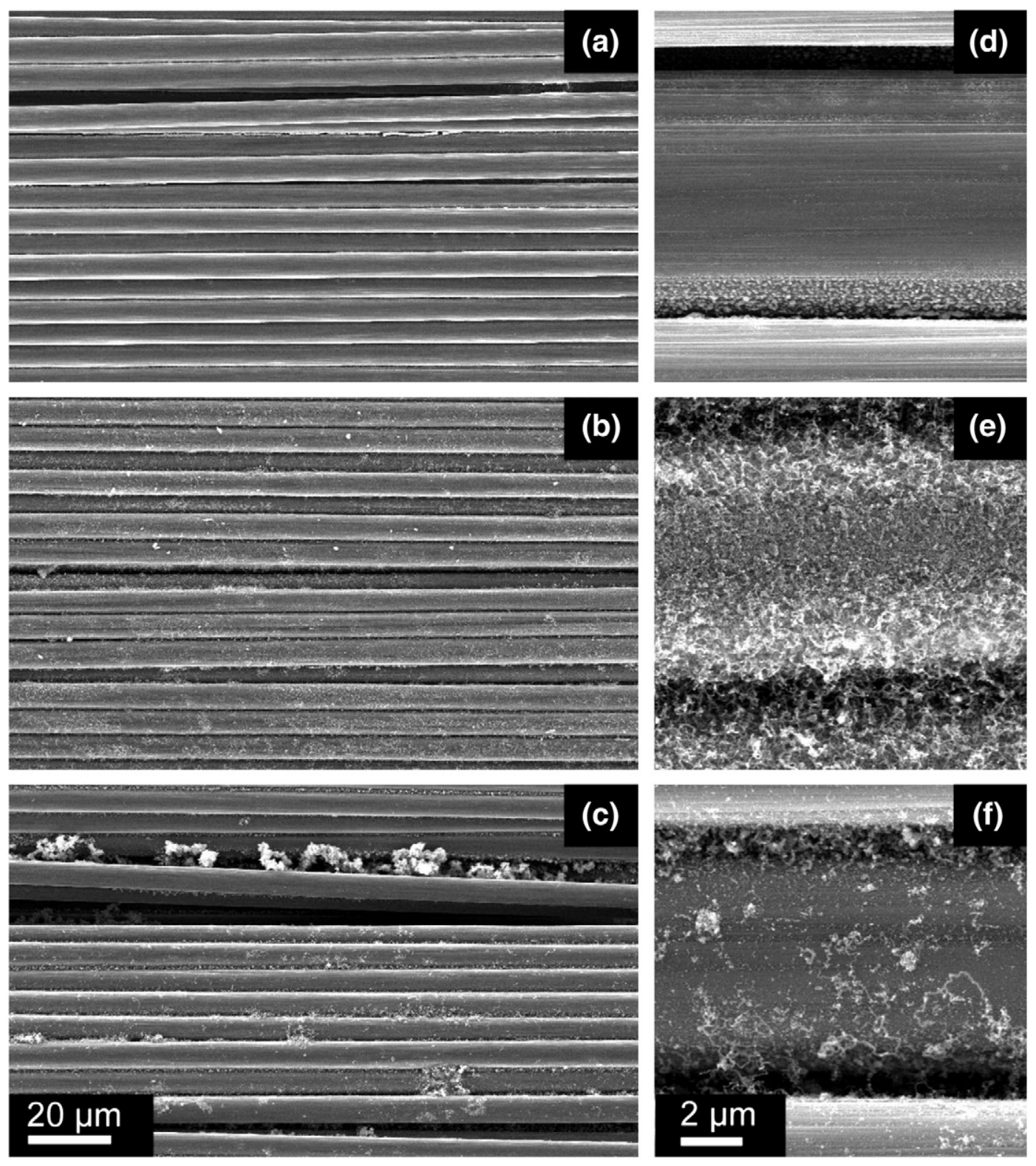

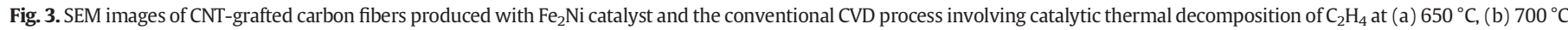
and (c) $750{ }^{\circ} \mathrm{C}$. (d), (e) and (f) show the respective enlargements.

interaction between catalyst particles and the carbon fiber surface, hence initiating tip-growth mode. Our observation is in agreement with the results reported by other groups: e.g. Thostenson et al. applied so far the lowest growth temperature of $660{ }^{\circ} \mathrm{C}$ [13] whereas others used temperatures higher than $700{ }^{\circ} \mathrm{C}$ [14-23].

Thus, the conventional CNT growth process was limited to a temperature range of $650^{\circ} \mathrm{C}$ to $750{ }^{\circ} \mathrm{C}$, with $700^{\circ} \mathrm{C}$ being the optimum temperature to obtain high number of CNTs grafted homogeneously on the carbon fibers. The lower limit of the CNT growth window can be explained by the limited thermal decomposition of hydrocarbon at temperatures below $650{ }^{\circ} \mathrm{C}$. In contrast, at high temperatures, agglomeration of the catalyst particles was promoted leading to large particles as well as to large diameter CNTs or even carbon nanofibers as verified by TEM (not shown).

\subsubsection{Equimolar growth}

As we reported previously [31-33], the oxidative dehydrogenation reaction between $\mathrm{C}_{2} \mathrm{H}_{2}$ and $\mathrm{CO}_{2}$ was a highly reproducible approach yielding significantly enhanced activity and lifetime of the catalyst so that a high yield of CNTs could be obtained at low temperatures without any arduous catalyst activation prior to the growth. Indeed, the carbon fibers exposed to the oxidative dehydrogenation reaction of $\mathrm{C}_{2} \mathrm{H}_{2}-\mathrm{CO}_{2}$ showed a weight difference which was positive for the whole temperature range from $500{ }^{\circ} \mathrm{C}$ to $750{ }^{\circ} \mathrm{C}$ and had a maximum at $650{ }^{\circ} \mathrm{C}$ with a weight gain of about $15 \%$. The observed maximum is a characteristic feature of the oxidative dehydrogenation reaction, where two chemical reaction paths are involved [31]:

$$
\begin{aligned}
& \mathrm{C}_{2} \mathrm{H}_{2}+\mathrm{CO}_{2} \rightarrow 2 \mathrm{C}+\mathrm{H}_{2} \mathrm{O}+\mathrm{CO} \\
& \mathrm{C}_{2} \mathrm{H}_{2}+\mathrm{CO}_{2} \rightarrow \mathrm{C}+2 \mathrm{CO}+\mathrm{H}_{2} .
\end{aligned}
$$

The reaction (1) occurs at lower temperature whereas the reaction (2) is kinetically preferred at higher temperature. Consequently, the quantity of CNTs produced strongly depends on the growth temperature applied. The maximum is directly correlated with the transition from the reaction path (1) to reaction path (2). For an equimolar stoichiometry between $\mathrm{C}_{2} \mathrm{H}_{2}$ and $\mathrm{CO}_{2}$, the carbon phase produced is entirely 
composed of CNTs, and no amorphous carbon is produced [31]. As can be seen in Fig. 2, at $500{ }^{\circ} \mathrm{C}$ the CNT growth was rather moderate with a weight gain of $2.45 \%$. This is roughly comparable with the highest weight gain (about 1\%) obtained by the conventional growth at $700{ }^{\circ} \mathrm{C}$ by taking the different CVD time into account (30 min and $10 \mathrm{~min}$, respectively).

The SEM images presented in Fig. 4 demonstrate the temperature dependence: At $500{ }^{\circ} \mathrm{C}$, CNTs formed on carbon fibers with a limited length but reached a homogeneous distribution. At $600{ }^{\circ} \mathrm{C}$, the CNTs showed an average length of several micrometers and thickly covered the carbon fiber surface. The radial dimension of carbon fiber was estimated from SEM images to about $8 \mu \mathrm{m}$, which was approximately $15 \%$ increased compared to the original diameter of $7 \mu \mathrm{m}$. However, the cross-sectional view of the carbon fibers processed at $600{ }^{\circ} \mathrm{C}$ shows (see Fig. 4f) that the thickness of the CNT layer was not homogeneous around the entire surface. Generally, CNTs appeared rather curly.

The CNT diameter was determined by means of TEM and its distribution is highlighted in Fig. 5b. Two maxima appear at about $30 \mathrm{~nm}$ and $55 \mathrm{~nm}$. The SEM images (Fig. 4c and d) indicate that especially CNTs formed between fibers were rather thick and highly curled. The TEM image in Fig. 5a confirms that CNTs are indeed strongly curled. The CNTs show very often a narrow inner wall diameter as well as fishbone or bamboo structure (see inset of Fig. 5a). For the growth carried out at $700{ }^{\circ} \mathrm{C}$, CNTs with a diameter of $30 \mathrm{~nm}$ and $60 \mathrm{~nm}$ were most predominantly found. Much thicker CNTs were also present, more frequent than for the sample processed at $600{ }^{\circ} \mathrm{C}$ indicating a much broader diameter distribution. At $750{ }^{\circ} \mathrm{C}$ mainly large-diameter and curly CNTs were produced due to catalyst particle agglomeration promoted at high temperatures. For the entire CVD temperature range, catalyst particles (can be seen as bright dots in the SEM images as well as marked by black arrows in Fig. 5a) appeared at the end of CNTs indicating the tip-growth mode. Also CNTs with an open end were frequently observed (e.g. marked by an open arrow in Fig. 5a), most probably where the catalyst particle had fallen off.

Fig. 6 presents the Raman spectra taken from carbon fibers after removal of the sizing and from carbon fibers with CNTs grown at $600{ }^{\circ} \mathrm{C}$ using the equimolar $\mathrm{C}_{2} \mathrm{H}_{2}-\mathrm{CO}_{2}$ reaction. For both samples the signals corresponding to the D and $\mathrm{G}$ bands are visible at $1331-1361 \mathrm{~cm}^{-1}$ and $1600 \mathrm{~cm}^{-1}$, which are associated with disordered and graphitized carbon, respectively [34]. In Raman spectra, the ratio of D and G bands $\left(\mathrm{I}_{\mathrm{D}} / \mathrm{I}_{\mathrm{G}}\right)$ can be regarded as a measure of the crystalline order of carbon materials. Carbon fibers without CNTs show broad peaks with linewidths of approximately $164 \mathrm{~cm}^{-1}$ (D band) and $106 \mathrm{~cm}^{-1}$ ( $G$ band), indicating a rather low degree of ordering of the graphitic structures. The bands significantly narrow down to about $154 \mathrm{~cm}^{-1}$ ( $D$ band) and $58 \mathrm{~cm}^{-1}$ ( $\mathrm{G}$ band) after the CVD process. Also the ratio of $D$ and $G$ bands $\left(I_{D} / I_{G}\right)$ decreases when carbon fibers are grafted with CNTs. The $\mathrm{I}_{\mathrm{D}} / \mathrm{I}_{\mathrm{G}}$ values are 0.83 and 0.9 for carbon fibers with and
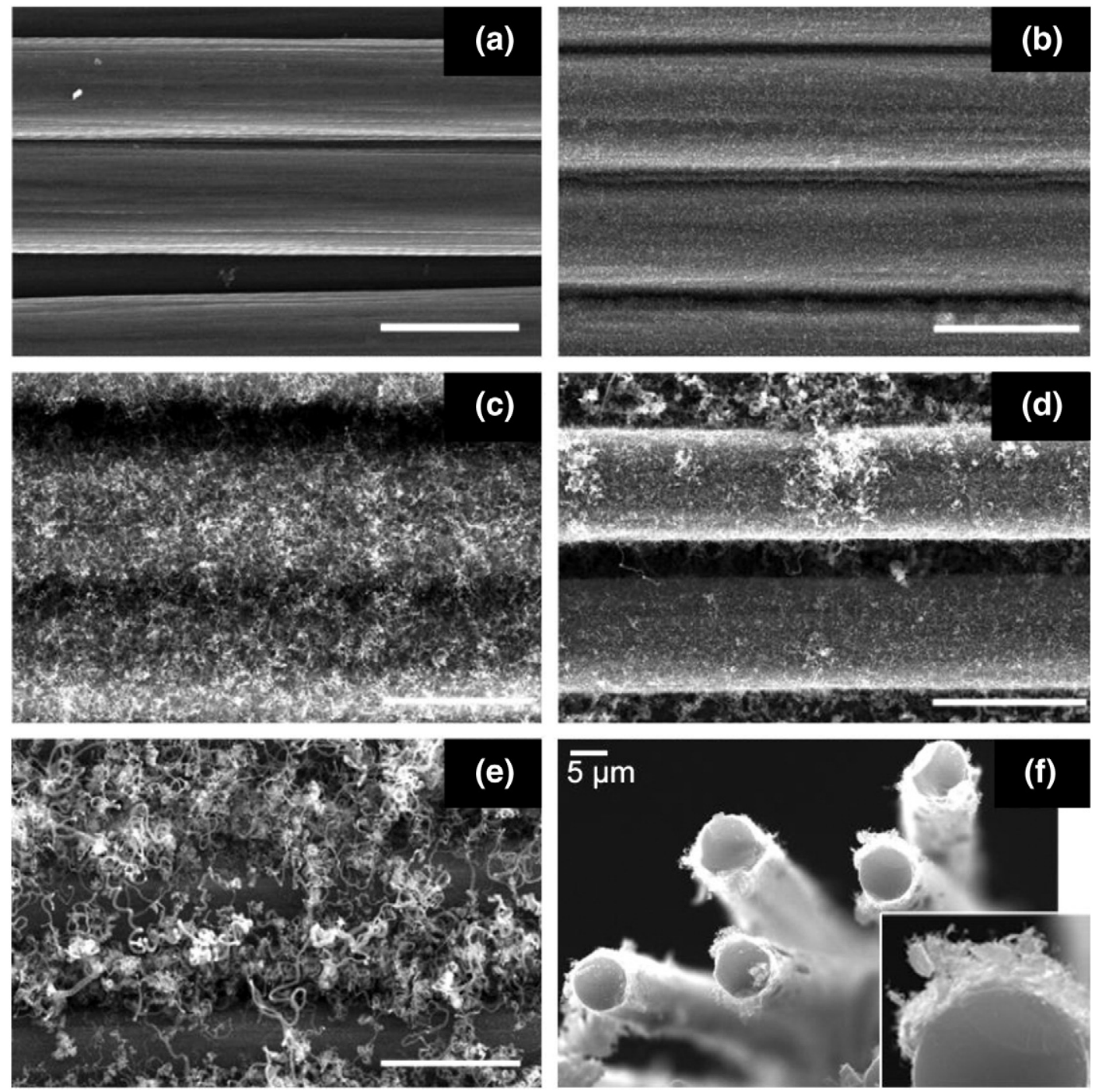

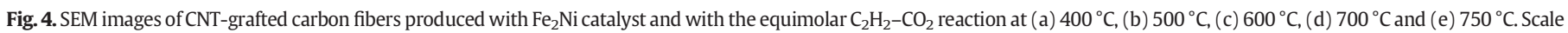
bars equal $10 \mu \mathrm{m}$. (f) shows a cross-sectional image of the carbon fibers processed at $600{ }^{\circ} \mathrm{C}$, including a higher magnification view in the inset. 

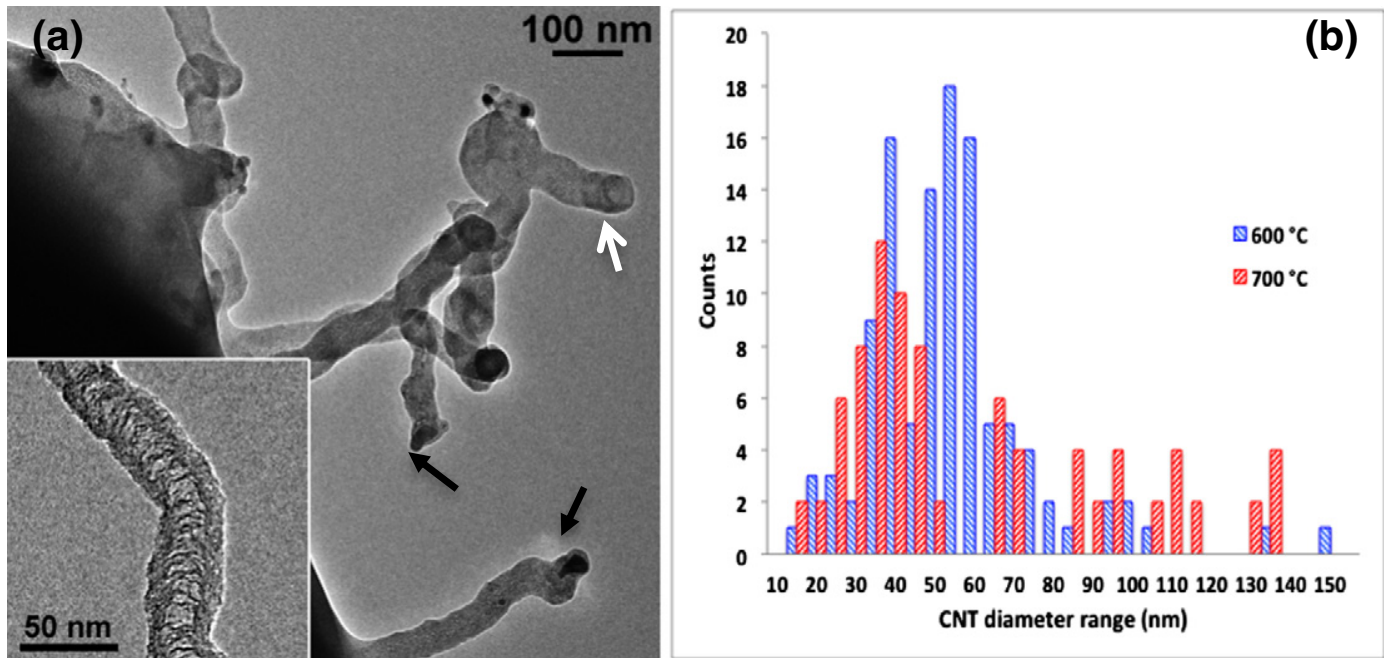

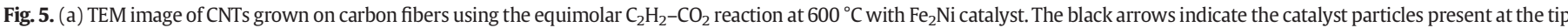

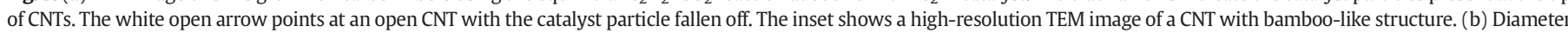
distribution of CNTs grown on carbon fibers at $600{ }^{\circ} \mathrm{C}$ and $700{ }^{\circ} \mathrm{C}$.

without CNTs, respectively. The relatively high intensity of the D band for the CNT-grafted carbon fibers (e.g. compared to typical D band measured in single-walled CNTs), confirms the present defective, curly structure of MWCNTs.

\subsection{Influence of catalyst composition}

The catalyst composition has a strong influence on the CNT growth because of the difference in catalytic efficiency, with the bimetallic catalysts generally being more efficient than mono-metallic ones. We studied $\mathrm{Fe}, \mathrm{Ni}$ and $\mathrm{Co}$ and selected as binary systems only $\mathrm{Fe}_{2} \mathrm{Ni}$ and $\mathrm{Fe}_{2} \mathrm{Co}$ because these compounds have been identified as the most efficient in the Fe-Ni and Fe-Co systems [27,33]. The SEM images in Fig. 7 show the CNT growth obtained by the conventional growth at $700{ }^{\circ} \mathrm{C}$ and the equimolar growth at $600{ }^{\circ} \mathrm{C}$, by using $\mathrm{Fe}, \mathrm{Ni}$ and $\mathrm{Fe}_{2} \mathrm{Ni}$ catalysts. These were the best temperatures for all catalyst compositions for the traditional and equimolar CVD process, respectively, as determined based on the weight gain (Fig. 2) and the SEM results (Figs. 3 and 4).

As can be seen in Fig. 7, carbon fibers were also thickly covered with CNTs for Fe and Ni catalysts after the conventional CVD process with

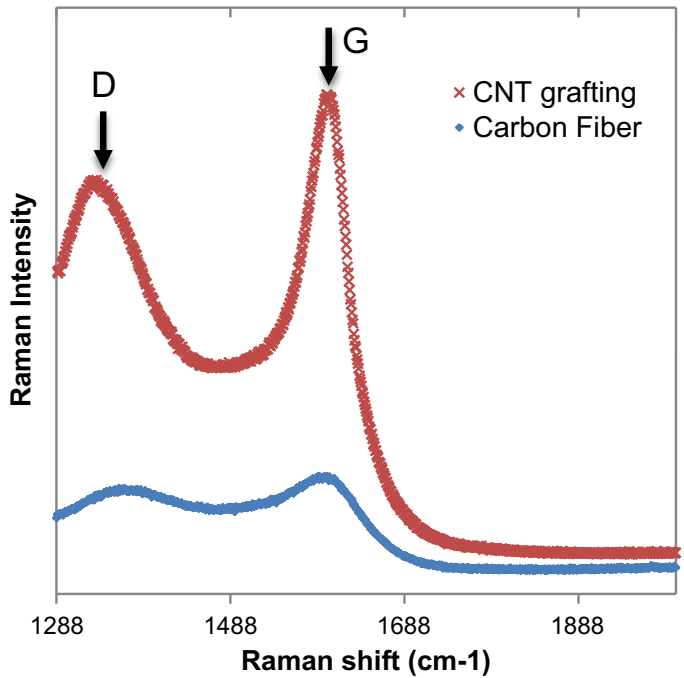

Fig. 6. Raman spectra $\left(\lambda_{\text {Laser }}=532 \mathrm{~nm}\right.$ ) of carbon fibers with and without the growth of CNTs. The D and G bands of the carbon fibers after the growth of CNTs confirm the higher ordering of the graphitic structures.
$\mathrm{Ar} / \mathrm{H}_{2} / \mathrm{C}_{2} \mathrm{H}_{4}$. However, the most homogeneous distribution was achieved with the $\mathrm{Fe}_{2} \mathrm{Ni}$ compound (Fig. 3b) with only small catalyst particles present at the CNT tips. Using Fe and Ni, larger particles were very often observed as well as carbon fiber surface remained partly without CNTs. The most inhomogeneous distribution was obtained when using $\mathrm{Ni}$ as catalyst: the carbon fibers were partly covered with dense CNTs, but about $20 \%$ of the surface was not covered. Especially between the fibers, many catalyst particles with a diameter in the range of several hundreds of $\mathrm{nm}$ were found, as can be seen in Fig. 7c. For the growth by means of the equimolar reaction between $\mathrm{C}_{2} \mathrm{H}_{2}$ and $\mathrm{CO}_{2}$ at $600{ }^{\circ} \mathrm{C}$, unlike with $\mathrm{Fe}_{2} \mathrm{Ni}$ (see Fig. 7f), Fe and Ni catalysts yielded significantly lower coverage with predominately uncovered carbon fiber surface (see Fig. 7b and d). $\mathrm{Fe}_{2} \mathrm{Ni}$ led to the most homogeneous coverage as well as the highest density and length of CNTs (Fig. 7e and f). Very similar results to $\mathrm{Fe}_{2} \mathrm{Ni}$ were obtained for $\mathrm{Fe}_{2} \mathrm{Co}$ (although not shown here). Hence, the bimetallic $\mathrm{Fe}_{2} \mathrm{Ni}$ and $\mathrm{Fe}_{2} \mathrm{Co}$ were also for carbon fibers also the most efficient catalyst composition within the $\mathrm{Fe}-\mathrm{Ni}$ and Fe-Co systems, respectively, for both CVD processes.

In literature, monometallic $\mathrm{Fe}$ and $\mathrm{Ni}$ catalysts have mainly been used for the CNT-grafting of carbon fibers. Zhao and coworkers have studied the CNT growth on carbon fibers using different kinds of transition metals, such as Fe, Ni and Co [35]. Unfortunately, they have not taken binary catalysts into account, which yield according to our observations the best homogeneity and narrow size distribution. Our results clearly indicate that monometallic catalyst particles promote larger catalyst particles as well as higher number of catalyst particles inactive for CNTs growth. As observed by SEM, surface damages were also more pronounced for monometallic catalysts than bimetallic ones.

When growing CNTs on carbon fibers, the catalytic reaction is strongly influenced by the carbon atoms originating from the interaction between the catalyst particles and the underlying carbon substrate. Carbon solubility is the lowest in $\mathrm{Fe}_{2} \mathrm{Ni}$ and $\mathrm{Fe}_{2} \mathrm{Co}$ and the highest in $\mathrm{Fe}$ and $\mathrm{Co}$. This might explain the damages caused by the large catalyst particles of Fe and Co as well as the inferior growth when Fe and Co catalysts were used. In contrast, bimetallic catalysts such as $\mathrm{Fe}_{2} \mathrm{Ni}$ and $\mathrm{Fe}_{2} \mathrm{Co}$ are excellent alternatives. As illustrated by Magrez et al. [27], $\mathrm{Fe}_{2} \mathrm{Co}$ and $\mathrm{Fe}_{2} \mathrm{Ni}$ catalysts transform upon annealing in an inert atmosphere to a single-phase catalyst. These phases have the highest catalytic efficiency in the $\mathrm{Fe}-\mathrm{Co}$ and $\mathrm{Fe}-\mathrm{Ni}$ systems. Together with the oxidative dehydrogenation reaction of $\mathrm{C}_{2} \mathrm{H}_{2}$ and $\mathrm{CO}_{2}$, which increases the catalytic activity even more, the catalyst lifetime and initial CNT growth rate are enhanced to such extent that the chemical interaction 


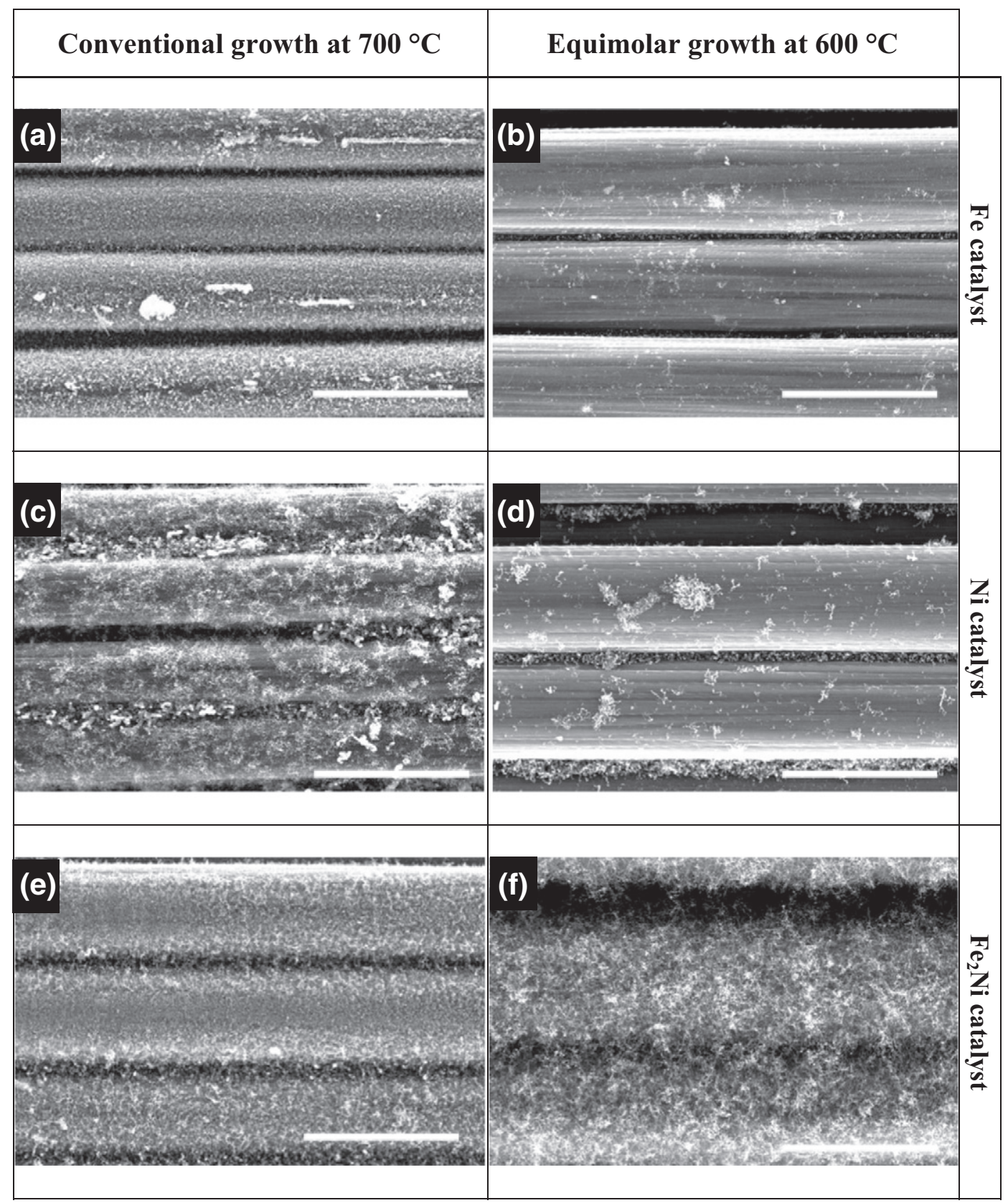

Fig. 7. SEM images of CNT-grafted carbon fibers produced with the conventional CVD process using the thermal decomposition of $\mathrm{C}_{2} \mathrm{H}_{4}$ at $700{ }^{\circ} \mathrm{C}$ and the equimolar $\mathrm{C}_{2} \mathrm{H}_{2}-\mathrm{CO}_{2}$ reaction at $600^{\circ} \mathrm{C}$, using three catalyst compositions: (a, b) Fe, (c, d) Ni and (e, f) Fe $2 \mathrm{Ni}$. Scale bars equal $10 \mu \mathrm{m}$.
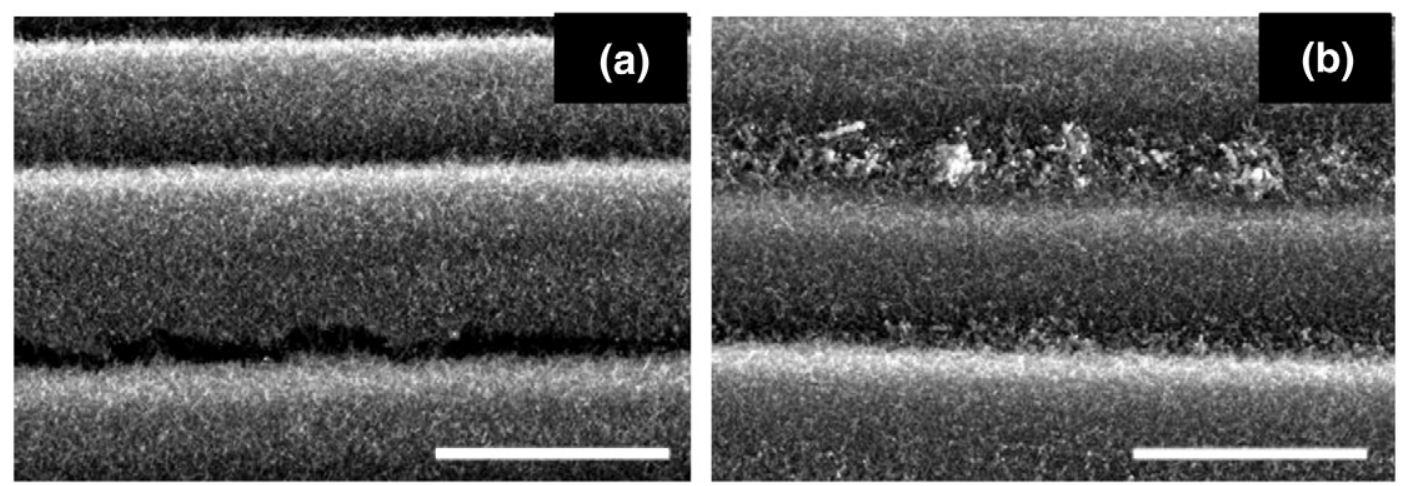

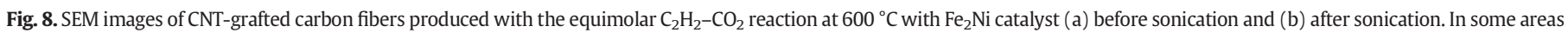
less dense CNTs are seen but most of the CNTs remained attached. Scale bars equal $10 \mu \mathrm{m}$ 
with the underlying carbon fiber becomes strongly limited resulting to less pronounced damages.

Our preliminary results indicate that an additional pretreatment of the catalysts with $\mathrm{Ar} / \mathrm{H}_{2}$ can improve the CNT characteristics even more: For the CNT-grafted carbon fibers produced with the equimolar reaction at $500{ }^{\circ} \mathrm{C}$ and $600{ }^{\circ} \mathrm{C}$ a weight gain of $6 \%$ and $9.8 \%$ was obtained, respectively. Compared with $2.5 \%$ and $6.3 \%$ weight gain obtained without the pretreatment (see Supporting information, Fig. S3), this was effectively an increase of about $146 \%$ and 59\%. SEM also confirmed that more dense and longer CNTs were obtained (not shown).

As a simple verification of the interfacial strength between CNTs and the carbon fiber surface, CNT-grafted fibers were sonicated in ethanol for $30 \mathrm{~min}$ at $40 \mathrm{kHz}$. Fig. 8 shows the SEM images of carbon fibers before and after sonication. In general, the CNTs remained well attached to the carbon fiber surface after sonication, although some areas were less covered by CNTs than before. The good adhesion was also confirmed by weight measurement before and after sonication: the weight gain (14.6 wt.\%) of the carbon fibers after the CNTs growth changed after sonication to 12.7 wt.\% indicating that up to $85 \%$ of the CNTs remained on the carbon fiber surface.

\subsection{Influence on the mechanical properties}

In Fig. 9, the tensile strength of CNT-grafted carbon fibers is shown as a function of the growth temperature for both, the CNT growth processed via the conventional thermal decomposition of $\mathrm{C}_{2} \mathrm{H}_{4}$ and via the equimolar reaction of $\mathrm{C}_{2} \mathrm{H}_{2}$ and $\mathrm{CO}_{2}$. As we previously reported [24], the carbon fiber stiffness was not affected by the growth process (see also Supporting information, Fig. S4), not even at temperatures as high as $700{ }^{\circ} \mathrm{C}$. This is due to the fact that the damages after the CVD process were limited to the fiber surface and did not proceed into the fiber core, which determines the stiffness.

On the contrary, the strain-to-failure (see Supporting information, Fig. S5) and strength were significantly affected by the CNT growth process. The decrease in strain-to-failure and strength scaled with the growth temperature: the higher the growth temperature, the higher the decrease. This was valid for both CVD processes. However, the decrease was significantly less for the growth using the equimolar $\mathrm{C}_{2} \mathrm{H}_{2}-\mathrm{CO}_{2}$ reaction: At $700{ }^{\circ} \mathrm{C}$, the fiber strength reduced to about $30 \%$ for the equimolar reaction compared to $47 \%$ for the conventional CVD process. Considering that homogeneous grafting with CNTs could only be achieved at $700{ }^{\circ} \mathrm{C}$ for the conventional CVD growth, lowering the growth temperature was only possible with the equimolar reaction between $\mathrm{C}_{2} \mathrm{H}_{2}$ and $\mathrm{CO}_{2}$. The data obtained from fibers after processing with the equimolar process at $500{ }^{\circ} \mathrm{C}$ and $600{ }^{\circ} \mathrm{C}$ showed that the strength remained comparable with the initial value. These results demonstrate that CNTs can effectively be

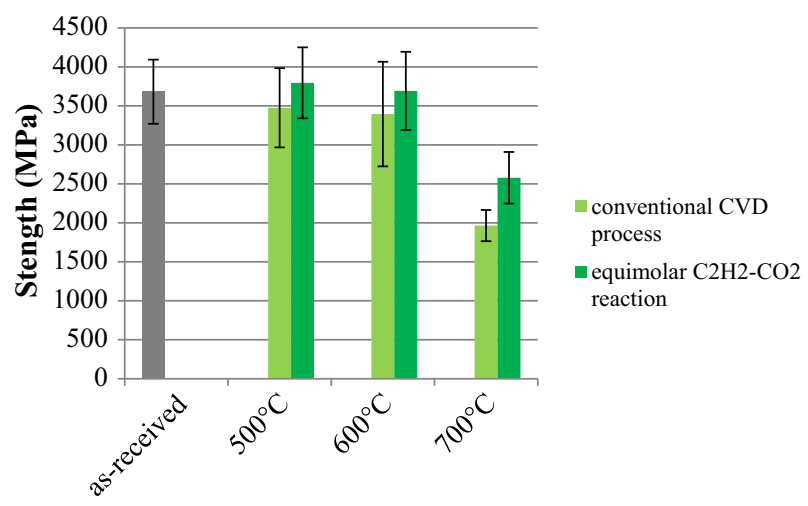

Fig. 9. Influence of growth temperature on the strength of the as-received fiber and CNTgrafted carbon fibers after CNT growth using $\mathrm{Fe}_{2} \mathrm{Ni}$ catalyst with the conventional CVD process ( $\square$ ) and the equimolar $\mathrm{C}_{2} \mathrm{H}_{2}-\mathrm{CO}_{2}$ reaction ( $\square$ ) at different temperatures. grown on carbon fibers by preventing damages by using reduced growth temperatures $\left(500-600{ }^{\circ} \mathrm{C}\right)$ combined with the oxidative dehydrogenation reaction between $\mathrm{C}_{2} \mathrm{H}_{2}$ and $\mathrm{CO}_{2}$.

To obtain more insight into the fiber strength, the data were further analyzed using Weibull statistics (Fig. 10). The as-received carbon fibers have a Weibull modulus of 4.91, which is a typical value for carbon fibers. After CNT growth using the conventional growth process at $700{ }^{\circ} \mathrm{C}$, the average fiber strength decreased by $53 \%$ while the Weibull modulus remained constant $(\mathrm{m}=4.83)$, indicating that the defects/flaws were distributed similarly in both samples but that their size had increased. There are two possible explanations: (i) additional bigger defects, besides the defects already present after manufacturing, were created during the CNT growth process by interaction of the catalytic particles with the carbon fibers at high temperature, as already shown before in Fig. 1c, and (ii) the catalytic particles preferentially attached to the initial manufacturing defects and the size of these defects increased during CNT growth. For the moment, no experimental evidence is available indicating one of both options. However when growing CNTs on carbon fibers using the equimolar reaction at $500{ }^{\circ} \mathrm{C}$, the Weibull modulus increased to 7.46 while the average fiber strength remained the same and even slightly improved. Consequently, we can conclude that no additional large defects were created and the already existing defects were partially healed during the CNTs growth process. Healing of the carbon fiber damages during the catalytic growth of CNTs has been reported recently by Kim et al. [21-23], although the precise process leading to healing was not yet well documented.

As mentioned in the Section 3.2, adding $\mathrm{H}_{2}$ during the $10 \mathrm{~min}$ of the pre-treatment prior to the $\mathrm{C}_{2} \mathrm{H}_{2} / \mathrm{CO}_{2}$ exposure increased the CNT density even more. Fig. 11 demonstrates that this $\mathrm{Ar} / \mathrm{H}_{2}$ pre-treatment also preserved (or even slightly improved) the tensile strength of the CNTgrafted carbon fibers. This result hints that further fine-tuning of the growth conditions can lead to significantly higher CNT density and possibly to higher tensile strength.

The influence of the different catalyst composition on the mechanical properties of CNT-grafted fibers, produced with the conventional CVD process, is summarized in Fig. 12. The decrease in fiber strength and strain-to-failure is most pronounced for the Fe catalyst. This observation is in agreement with our SEM results (see Section 3.2): Fe led to catalyst particles with the largest diameter compared to $\mathrm{Ni}$ or $\mathrm{Fe}_{2} \mathrm{Ni}$ (see Fig. 7c and e). Most of these large Fe particles did not lead to CNT growth and rather promoted large surface defects on the fiber surface with a size of about half of the catalyst diameter, in agreement with the previous report [36].

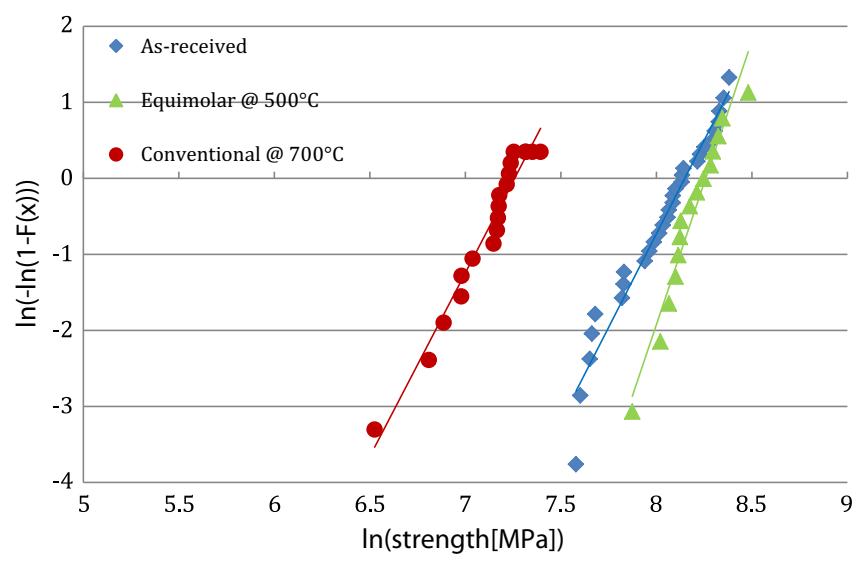

Fig. 10. Weibull plots for as-received carbon fibers (blue $\diamond$ ), CNT-grafted fibers produced with the conventional CNT growth process at $700^{\circ} \mathrm{C}$ (red $\bullet$ ) and CNT-grafted carbon fibers produced with the equimolar reaction at $500{ }^{\circ} \mathrm{C}$ (green $\triangle$ ). 


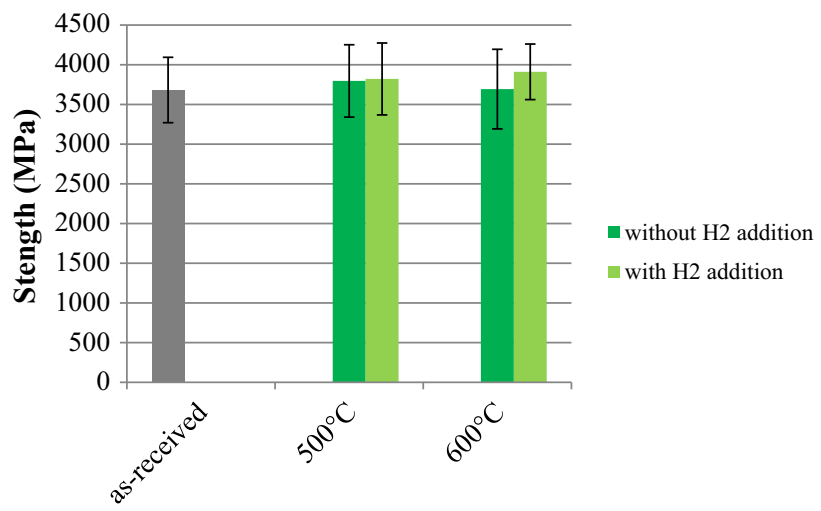

Fig. 11. Influence of $\mathrm{H}_{2}$ addition on the strength of the as-received fiber and CNT-grafted carbon fibers after $\mathrm{CNT}$ growth with the equimolar $\mathrm{C}_{2} \mathrm{H}_{2}-\mathrm{CO}_{2}$ reaction using $\mathrm{Fe}_{2} \mathrm{Ni}$-catalyst (without $\mathrm{H}_{2}$ addition $=\mathrm{n}$, with $\mathrm{H}_{2}$ addition $=\mathrm{m}$ ).

As already discussed in Section 3.2., Fe has higher carbon solubility compared to $\mathrm{Fe}_{2} \mathrm{Ni}$ or $\mathrm{Ni}$ and therefore leads to higher consumption of carbon from the fiber surface leaving much larger defects behind, which significantly reduce the tensile strength of the carbon fiber. Hence, it is evident that large catalyst particles present on carbon fibers result in large damages, yielding a large decrease in fiber strength. This can be seen in the following formula from fracture mechanics of brittle materials:

$\sigma_{f}=\sqrt{\frac{E_{f} \cdot G_{f c}}{\pi \cdot c}}$

where $\sigma_{f}$ represents the fiber strength, $E_{f}$ the Young's modulus, $G_{f c}$ the fracture toughness and $c$ the defect size of the carbon fiber. The larger the defect size $c$ present on the surface of the carbon fiber, the lower the strength of the carbon fiber will be. For monometallic Co (not shown here), we have observed a similar behavior as for monometallic Fe catalyst.

Most of the studies reporting CNT grafting of carbon fibers have used Fe as catalyst and observed significant damage of the carbon fiber surface, in agreement with our observations. However, Kim and coworkers reported that $\mathrm{Ni}$ catalysts led to formation of graphitic layers fully or partially wrapping the carbon fibers [21-23]. They claimed that these graphitic layers were formed after sputtering and annealing before the CVD process, based on carbons originating from the carbon fiber. The same group reported that by controlling the catalyst layer thickness and the CVD conditions, the tensile strength of carbon fibers could be increased up to $14 \%$ [22].

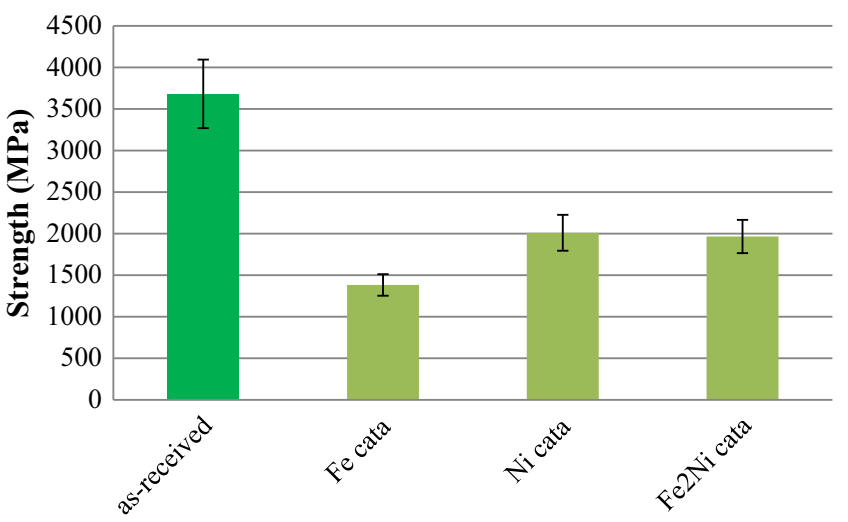

Fig. 12. Influence of the catalyst composition on the strength of the carbon fibers after CNT grafting using the conventional CVD process at $700{ }^{\circ} \mathrm{C}$. The strength of the as-received fiber is inserted as reference.
Our results together with the results reported in literature indicate that many different parameters impact the resulting tensile strength of the CNT-grafted carbon fibers. For instance, our catalyst deposition method based on impregnation with the catalyst solution and subsequent drying at $80{ }^{\circ} \mathrm{C}$ did not show any noticeable degradation of the tensile strength. In contrast, Kim et al. observed slight carbon fiber damages occurring already after sputter deposition of $\mathrm{Ni}$ at room temperature [21]. This indicates that the carbon fiber surface is fragile and can be damaged via the impact of the sputtered atoms from the target. However, the most significant deterioration occurs with the subsequent anneal at higher temperature $\left(750^{\circ} \mathrm{C}\right)$ to form catalyst nanoparticles. We observed a decrease of the strength for about 15-22\% after annealing at $700{ }^{\circ} \mathrm{C}$, which is slightly higher than $11 \%$ reported by Kim et al. [21].

In order to better identify the process parameter responsible for the carbon fiber damage, we have also studied the mechanical strength of carbon fibers after each process step (see Supporting information, Fig. S6): Carbon fibers without catalyst did not show any decrease in tensile strength when exposed to $700{ }^{\circ} \mathrm{C}$ in Ar. However, $700{ }^{\circ} \mathrm{C}$ combined with either the presence of catalyst particles or the exposure to the reactive gasses already decreased the tensile strength to about $80 \%$ and 70\%, respectively. Nevertheless, the major damage occurred (reduction to about $47 \%$, see Fig. 12) when both conditions were combined with $700{ }^{\circ} \mathrm{C}$, namely, when carbon fibers impregnated with catalyst particles were exposed to the reactive gasses.

In summary, it can be stated that the catalytic growth of CNTs on carbon fiber surfaces strongly depends on the precise process conditions, such as the CVD temperature, growth time, gas mixture and flow rate, catalyst composition and density, catalyst deposition method, and also on the type of carbon fibers used. Hence, healing as reported by Kim et al. [21] might be difficult to precisely reproduce and also to implement in industrial processes. In contrast, our approach aimed at preventing fiber damages before their generation. Already our catalyst deposition is significantly less harmful and also viable for up-scaling. Nevertheless, the oxidative dehydrogenation reaction allows us growing CNTs successfully as low as $500{ }^{\circ} \mathrm{C}$ without degradation of the mechanical properties of the carbon fibers. As the reaction is very simple to control by adjusting the $\mathrm{C}_{2} \mathrm{H}_{2}-\mathrm{CO}_{2}$ ratio to $1: 1$, we think that this process is suitable for up-scaling and can make the CNT-grafted CFRC to a viable technology.

\section{Conclusion}

In conclusion, CNTs were grown directly on the surface of carbon fibers using two CVD recipes: (i) traditional CNT growth process based on thermal decomposition of ethylene and (ii) oxidative dehydrogenation reaction between $\mathrm{C}_{2} \mathrm{H}_{2}$ and $\mathrm{CO}_{2}$. For the traditional CVD process, weight measurements and SEM investigation identified $700{ }^{\circ} \mathrm{C}$ being the optimum growth temperature to obtain high yield of homogeneously distributed CNTs on the fiber surface.

Single-fiber tests of CNT-grafted carbon fibers indicated that the CVD process strongly damaged the fiber surface. Especially, the interaction between the high CVD process temperature and the carbon fibers on the one hand, and the interaction between catalytic particles and reactive gasses on the other hand, were found to be responsible for the fiber surface damages, resulting in a strongly decreased fiber strength and strain-to-failure. This decrease was less pronounced at lower growth temperatures and was even negligible at growth temperature below $600{ }^{\circ} \mathrm{C}$. However, the traditional CNT growth process was not effective at low temperatures because the decomposition of hydrocarbon is kinetically limited.

This problem was tackled by using an alternative route, namely the equimolar $\mathrm{C}_{2} \mathrm{H}_{2}-\mathrm{CO}_{2}$ reaction. With this growth process, CNTs were successfully grown on the carbon fiber surface at temperatures as low as $500{ }^{\circ} \mathrm{C}$. Single-fiber tests indicated that the fiber surface remained intact after the growth process, resulting in CNT-grafted carbon fibers 
with the same strength and strain-to-failure as the as-received fibers. The Weibull modulus indicated that no additional large defects were created during the equimolar $\mathrm{C}_{2} \mathrm{H}_{2}-\mathrm{CO}_{2}$ reaction and that already existing defects were partially healed during the CVD process. These results can be an important step towards CNT-engineered CFRCs with a much stronger fiber/matrix interface and damage resistance, in particular because the process is precisely controllable and suitable for upscaling.

\section{Prime novelty statement}

We recently reported on our approach to grow carbon nanotubes (CNTs) directly onto carbon fiber without damages to the carbon fiber surface (De Greef et al., Phys. Stat. Sol. 2012). In this work, we have systematically studied the influence of the different parameters of the CVD process on the CNT characteristics as well as the mechanical properties of the carbon fibers. To our knowledge, this is the first paper giving a detailed insight into the direct growth of CNTs on carbon fibers where high density of CNTs could be obtained without damaging the carbon fibers.

\section{Acknowledgment}

N.D.G. acknowledges FWO fellowship for PhD. J.W.S. thanks the Flemish Hercules Stichting for their support in HER/08/25 and the KU Leuven for the support in STRT1/08/025 as well as in GOA/10/004. I.V. thanks Toray for being holder of the Toray Chair of Composites at KU Leuven. J.P.L. acknowledges FWO for the Odysseus Program. We also thank L. Gorbatikh, S.V. Lomov, E. Nies, B. Goderis and L. Gonzalez Urbina for their useful discussions. L. Bernard is acknowledged for the micro-Raman measurements.

\section{Appendix A. Supplementary data}

Supplementary data to this article can be found online at http://dx. doi.org/10.1016/j.diamond.2014.11.002.

\section{References}

[1] E.T. Thostenson, Z.F. Ren, T.W. Chou, Advances in the science and technology of carbon nanotubes and their composites: a review, Compos. Sci. Technol. 61 (2001) 1899-1912.

[2] E.T. Thostenson, C. Li, T.W. Chou, Nanocomposites in context, Compos. Sci. Technol. 65 (2005) 491-516.

[3] B. Fiedler, F.H. Gojny, M.H.G. Wichmann, M.C.M. Nolte, K. Schulte, Fundamental aspects of nano-reinforced composites, Compos. Sci. Technol. 66 (2006) 3115-3131.

[4] H. Qian, E.S. Greenhalgh, M.S.P. Shaffer, A. Bismarck, Carbon nanotube-based hierarchical composites: a review, J. Mater. Chem. 20 (2010) 4751-4762.

[5] T.W. Chou, L.M. Gao, E.T. Thostenson, Z.G. Zhang, J.H. Byun, An assessment of the science and technology of carbon nanotube-based fibers and composites, Compos. Sci. Technol. 70 (2010) 1-19.

[6] A. Godara, L. Mezzo, F. Luizi, A. Warrier, S. Lomov, A.W. van Vuure, L. Gorbatikh, P. Moldenaers, I. Verpoest, Influence of carbon nanotubes reinforcement on the processing and the mechanical behaviour of carbon fiber/epoxy composites, Carbon 47 (2009) 2914-2923.

[7] N. De Greef, L. Gorbatikh, A. Godara, L. Mezzo, S.V. Lomov, I. Verpoest, The effect of carbon nanotubes on the damage development in carbon fiber/epoxy composites, Carbon 49 (2011) 4650-4664.

[8] N. De Greef, L. Gorbatikh, S.V. Lomov, I. Verpoest, Damage development in woven carbon fiber/epoxy composites modified with carbon nanotubes under static tension in the bias direction, Compos. Part A-Appl. S. (2011) 1635-1664.

[9] E.J. Garcia, B.L. Wardle, A.J. Hart, Joining prepreg composite interfaces with aligned carbon nanotubes, Compos. Part A 39 (2008) 1065-1070.
[10] P. Lv, Y. Feng, P. Zhang, H. Chen, N. Zhao, W. Feng, Increasing the interfacial strength in carbon fiber/epoxy composites by controlling the orientation and length of carbon nanotubes grown on the fibers, Carbon 49 (2011) 4665-4673.

[11] W.B. Downs, R.T.K. Baker, Novel carbon fiber-carbon filament structures, Carbon 29 (1991) 1173-1179.

[12] W.B. Downs, R.T.K. Baker, Modification of the surface properties of carbon fibers via the catalytic growth of carbon nanofibers, J. Mater. Res. 10 (1995) 625-633.

[13] E.T. Thostenson, W.Z. Li, D.Z. Wang, Z.F. Ren, T.W. Chou, Carbon nanotube/carbon fiber hybrid multiscale composites, J. Appl. Phys. 91 (2002) 6034-6037.

[14] M.F. De Riccardis, D. Carbone, T.D. Makris, R. Giorgi, N. Lisi, E. Salernitano, Anchorage of carbon nanotubes grown on carbon fibres, Carbon 44 (2006) 671-674.

[15] R.B. Mathur, S. Chatterjee, B.P. Singh, Growth of carbon nanotubes on carbon fibre substrates to produce hybrid/phenolic composites with improved mechanical properties, Compos. Sci. Technol. 68 (2008) 1608-1615.

[16] H. Qian, E.S. Greenhalgh, M.S.P. Schaffer, A. Bismarck, Hierarchical composites reinforced with carbon nanotube grafted fibers: the potential assessed at the single fiber level, Chem. Mater. 20 (2008) 1862-1869.

[17] S.P. Sharma, S.C. Lakkad, Effect of CNTs growth on carbon fibers on the tensile strength of CNTs grown carbon fiber-reinforced polymer matrix composites, Compos. Part A 42 (2011) 8-15.

[18] F. An, C. Lu, Y. Li, J. Guo, X. Lu, H. Lu, S. He, Y. Yang, Preparation and characterization of carbon nanotube-hybridized carbon fiber to reinforce epoxy composite, Mater. Des. 33 (2012) 197-202.

[19] Q. Zhang, J. Liu, R. Sager, L. Dai, J. Baur, Hierarchical composites of carbon nanotubes on carbon fiber: influence of growth condition on fiber tensile properties, Compos. Sci. Technol. 69 (2009) 594-601.

[20] K. Naito, J.-M. Yang, Y. Tanaka, Y. Kagawa, Tensile properties of carbon nanotubes grown on ultrahigh strength polyacrylonitrile-based and ultrahigh modulus pitchbased carbon fibers, Appl. Phys. Lett. 92 (2008) 231912.

[21] K.J. Kim, W.-R. Yu, J.H. Youk, J. Lee, Degradation and healing mechanisms of carbon fibers during the catalytic growth of carbon nanotubes on their surfaces, ACS Appl. Mater. Interfaces 4 (2012) 2250-2258.

[22] K.J. Kim, J. Kim, W.-R. Yu, J.H. Youk, J. Lee, Improved tensile strength of carbon fibers undergoing catalytic growth of carbon nanotubes on their surface, Carbon 54 (2013) 258-267.

[23] K.J. Kim, W.-R. Yu, J.H. Youk, J. Lee, Factors governing the growth mode of carbon nanotubes on carbon-based substrates, Phys. Chem. Chem. Phys. 14 (2012) 14041-14048.

[24] N. De Greef, A. Magrez, E. Couteau, J.-P. Locquet, L. Forro, J.W. Seo, Growth of carbon nanotubes on carbon fibers without strength degradation, Phys. Status Solidi B 249 (2012) 2420-2423.

[25] K.J. Kim, J.M. Lee, J.H. Youk, W.-R. Yu, Carbon nanotube grafted carbon fibers: optimum process, Proceedings of the 17th International Conference on Composite Materials ICCM17, Edinburgh, UK, July 27-31, 2009, 2009, p. E1.21.

[26] G. Lee, K.J. Kim, W.-R. Yu, J.H. Youk, The effect oft he surface roughness of carbon fibres on CNT grown by floating-catalyst chemical vapour deposition, Int. J. Nanotechnol. 10 (2013) 800-810.

[27] A. Magrez, J.W. Seo, C. Mikó, K. Hernadi, L. Forró, Growth of carbon nanotubes with alkaline earth carbonate as support, J. Phys. Chem. B 109 (2005) 10087-10091.

[28] W.P. Hoffman, W.C. Hurley, P.M. Liu, T.W. Owens, The surface topography of nonshear treated pitch and PAN carbon fibers as viewed by the STM, J. Mater. Res. 6 (1991) 1685-1694.

[29] W.P. Hoffman, Scanning probe microscopy of carbon fiber surfaces, Carbon 30 (1992) 315-331.

[30] P. Marshall, J. Price, Topography of carbon-fiber surface, Composites 22 (1991) 388-393.

[31] A. Magrez, J.W. Seo, R. Smajda, B. Korbely, J.C. Andresen, M. Mionic, S. Casimirius, L Forró, Low-temperature, highly efficient growth of carbon nanotubes on functional materials by an oxidative dehydrogenation reaction, ACS Nano 4 (2010) 3702-3708.

[32] A. Magrez, J.W. Seo, V. Kuznetsov, L. Forró, Evidence of an equimolar $\mathrm{C}_{2} \mathrm{H}_{2}-\mathrm{CO}_{2}$ reaction in the synthesis of carbon nanotubes, Angew. Chem. Int. Edit. 46 (2007) 441-444.

[33] A. Magrez, J.W. Seo, R. Smajda, M. Mionic, L. Forró, Catalytic CVD synthesis of carbon nanotubes: towards high yield and low temperature growth, Materials 3 (2010) 4871-4891.

[34] M. Dresselhaus, A. Jorio, R. Saito, Characterizing graphene, graphite, and carbon nanotubes by Raman spectroscopy, Annu. Rev. Condens. Matter Phys. 1 (2010) 89-108.

[35] J. Zhao, L. Liu, Q. Guo, J. Shi, G. Zhai, J. Song, Z. Liu, Growth of carbon nanotubes on the surface of carbon fibers, Carbon 46 (2008) 365-389.

[36] H. Qian, A. Bismarck, E.S. Greenhalgh, M.S.P. Shaffer, Synthesis and characterisation of carbon nanotubes grown on silica fibres by injection CVD, Carbon 48 (2010) $277-286$. 